\title{
Modelling and transient simulation of a regenerative open Joule cycle reciprocating Ericsson engine for micro-CHP applications
}

\author{
Frederic LONTSI ${ }^{\# *}$, Oumarou HAMANDJODA^, Pascal STOUFFS! and Jean NGANHOU^ \\ \#Faculty of Industrial Engineering, EDSFA/UFD SI, University of Douala, 2701 Douala, Cameroon \\ ${ }^{\wedge}$ Department of Mechanical and Industrial Engineering, ENSP, University of Yaounde 1, 8390 Yaoundé, Cameroon \\ 'Laboratoire de Thermique, Energétique et Procédés (LaTEP), Université de Pau et des Pays de l'Adour, 64000 Pau, France
}

Received 02 May 2018, Accepted 28 June 2018, Available online 30 June 2018, Vol.8, No.2 (June 2018)

\begin{abstract}
The open Joule cycle reciprocating Ericsson engine shows promising results as regards small-scale cogeneration applications using renewable energies such as biomass or solar energy. Integrating a regenerative heat exchanger into a simple open Joule cycle helps to improve the engine performance thanks to the recovery of the waste heat of hot gases downstream the expander. A dynamic model of a small open Joule cycle Ericsson engine with a shell-andtube counter-flow regenerative heat exchanger is developed and simulated in order to study the operation stability, the system behaviour especially during transient phases, and the control strategies. Compared to the engine configuration without regeneration, simulation results predict a slower hot start-up transient followed by a stable operation of the engine with 21\% increase of the engine thermal efficiency, $14.3 \%$ increase of the engine power output and a $529.5 \mathrm{~K}$ exhaust air flow suitable for cogeneration purposes. Subjected to a selected perturbation (10kPa compressor inlet pressure drop) the engine reacts well and the operation is stabilized after a much longer transient phase. Valve settings are also addressed to maintain the system set pressure.
\end{abstract}

Keywords: Joule cycle reciprocating engine, recuperator, modelling, transient simulation, micro-CHP

\section{Introduction}

The thermodynamic conversion of energy from fossil fuels is generally accompanied by emissions of greenhouse gases and other pollutants whose negative impact on the environment is well known. It is for this reason that energy efficiency and the use of renewable energy sources must be taken into account when designing thermal energy conversion systems, particularly as concerns thermal engines. The reciprocating Joule cycle heat engine (Ericsson engine) seems to have significant advantages compared to the internal combustion engine when designed for small scale applications. This has been highlighted in the classifications of heat engines (Stouffs, 2002). In fact, the Ericsson engine is compatible with any type of energy source and adequately fulfills environmental requirements.These advantages provide an alternative to existing systems, within a range of applications such as micro-combined heat and power (CHP) in residential areas;valorization of biomass in remote sites for electricity generation; or thermodynamic valorizationof solar energy (Lontsi, et al, 2013).

*Correspoding author's Tel: +237 77604287

ORCID ID: 0000-0003-4038-9295

DOI: https://doi.org/10.14741/ijtt/v.8.2.3
The Joule cycle reciprocating Ericsson engine seems more suitable for thermal energy conversion in the low power range (Bonnet, et al, 2005). From existing literature, some studies have reported theoretical developments on reciprocating Joule cycle engines on particular aspects including thermodynamic optimization, design and performance study in view of their implementation in the cogeneration sector. Bell and Partridge (Bell and Partridge, 2003) conducted a study on an open Joule cycle reciprocating engine with regeneration, intended to be implemented in the CHP system and decentralized power generation. Despite the performance recorded and some similarities with the Ericsson engine, it should be noted that the machine described, however, differs from the latter by its combustion chamber. In a study conducted by Moss (Maoss, et al, 2005) on a Joule cycle reciprocating engine similar to that described above and intended for household micro-CHP, the problem of dimensioning was examined. The study predicts a thermal efficiency of $35 \%$ and an overall electrical efficiency of $33.2 \%$. However, this level of performance is explained by the relatively high values of the pressure ratio (equivalent to 7.5 ) and the engine rotation speed (1000rpm).

In recent literature, some Ericsson engine models have been developed on the basis of open Joule cycle for micro-CHP applications particularly that which is 
based on aspects of thermodynamic optimisation of the engine performances (Creyx, et al, 2013) while the other has established a relationship between the geometrical characteristics, the operating parameters and energy performance, useful for the design of the engine (Touré and Stouffs, 2014).

Houda et al. (Houda, et al, 2015) established the exergetic models of a 500W Gamma type Stirling engine and a 300W open cycle Ericsson engine without heat recovery in order to quantify the exergy destruction and efficiencies in each type of engine and to compare them. The simulation result of these steady-state models showed that the Stirling engine presents higher global performance. The importance of the Ericsson engine preheater/recuperator to supply the expansion cylinder with a high exergy flux has also been highlighted. According to this study, the exergy recovered reaches about $25 \%$ of the destroyed exergy. The gap between Stirling and Ericsson engines performances might be reduced using a preheater/recuperator in the Ericsson engine.

Furthermore, the exergetic efficiency gap can be filled with an injection of exhaust gas in the combustion process of the cogeneration unit. However, none of these steady state models takes into account transient phases or pressure drops through inlet and exhaust valves of the compression and expansion cylinders.

A dynamic model ofa $25 \mathrm{~kW}$ externally heated reciprocating valve engine based on the closed Joule cycle was developed by Wojewoda and Kazimierski (Wojewoda and Kazimierski, 2010) in order to describe the operating conditions of such an engine.The simulations carried out showed that this highly pressurized air engine (compressed air from 15 to 95bar) could reach a thermal efficiency of up to $25 \%$. However, in order to achieve this level of performance, the system requires a high rotational speed $(3000 \mathrm{rpm})$. Moreover, startup transient concerns have not been addressed, as well as those related to heat recovery since the study involved a closed Joule cycle.

Lontsi et al. (Lontsi, et al, 2013) also have developed a dynamic model of a $1.67 \mathrm{kWsmall}$ Joule cycle reciprocating engine in order to study the operation stability and to control its behaviour especially during transient phases. Simulations of the dynamics of starting and steady conditions were carried out in that study and the results obtained have predicted a rapid hot starting (achieved in about 5.3 seconds) followed by a stable operation of the engine which is stabilized, with a thermal efficiency of approximately $29 \%$. This work also showed that subjected to some selected perturbations, the system has responded well. Despite the level of performance obtained in this work, the engine model does not, however, take into account heat recovery since the configuration of the Ericsson engine adopted was based on an open Joule cycle without regeneration.

In the literature, there are some recent research works on the modeling and simulation of Ericsson engines. One of these studies (Frederic Lontsi, et al,
2013) focuses on the engine configuration when operating based on a modified open Joule cycle (by cooling the compression cylinder to increase overall power at the expense of thermal efficiency).The other one deals specifically on modeling the dynamics of the engine's expansion cylinder using the bond graph approach (Creyx, et al, 2016). In both cases, various factors are taken into account (pressure drops, heat transfers through working cylinders, etc.) and the study of the dynamic of the operation of the system is carried out with a view to microcogeneration applications. However, the systems are described by open cycles and the heat recovery is not taken into account in the developed models

More recently, Dorin Stanciu and Viorel Badescu (Stanciu and Badescu, 2017) presented and modeled a solar-driven Joule cycle reciprocating Ericsson engine designed for small scale applications taking into account phenomena such as the gas undercompression occurring in compressor cylinder and the over-compression and/or over-expansion of the gas happening in the expander cylinder, as well as setting the proper strategy to switch between different rotation speeds in order to increase the work generated per day. The model of the engine developed also does not take into account heat recovery in the considered open Joule cycle.

Integrating a regenerative heat exchanger (recuperator) into a simple open Joule cycle leads to improved Ericsson engine performance thanks to the recovery of the waste heat of hot gases downstream the expander. In this work, a dynamic model of the engine is developed and simulated, considering its configuration based on the open Joule cycle with regeneration. Particular emphasis is given to the design and modelling of the recuperator to enable the understanding of the operation of the system and the analysis of its behavior during simulations carried out both during the start-up and during the phases when the engine operation is stabilized. First, the studied configuration of the engine is presented. Then the modeling of the system followed by the presentation and the analysis of the simulation results are carried out with a special focus on the regenerator.

\section{Description of the studied regenerative open Joule cycle Ericsson engine}

From the thermodynamics point of view, the Ericsson engine is similar to a gas turbine where the turbo compressor has been replaced by a reciprocating compressor and the turbine by a piston/cylinder machine. The theoretical cycle of Ericsson (2 isotherms and 2 isobars) is not adapted to describe an ideal Ericsson engine (Creyx, et al, 2013), (Alaphilippe, et al, 2007). In an ideal Ericsson engine, heat transfers should take place at constant pressure while compression and expansion are supposed to be isentropic, corresponding to the Joule cycle, often used to describe the gas turbine principle. The Ericsson 
engine can be carried out either by a closed cycle with cooler (in this case the system can run at high pressure and allows the use of working fluids such as helium or hydrogen), or by an open cycle with or without regeneration (in this case, the working fluid is air that can be expanded down to the atmospheric pressure). The open cycle was identified to correspond to present needs in the field of domestic micro-CHP, as well as for solar or wood-energy conversion of energy into electricity $[3,13]$. In these machines, the compressor and the expansion cylinder run at low rotational speed, in order to limit the pressure losses due to the valves and also to reduce the mechanical losses. This solution ensures the best performances. During the engine operation in the configuration shown in figure 1, atmospheric air is sucked and compressed by the compressor C (thanks to the work input $\dot{W}_{c}$ ).It then receives heat $\left(\dot{Q}_{h}\right)$ from the hot source through the heater $\mathrm{H}$. The pressurized hot air produces work $\left(\dot{W}_{e}\right)$ by expansion in the expansion cylinder $\mathrm{E}$.

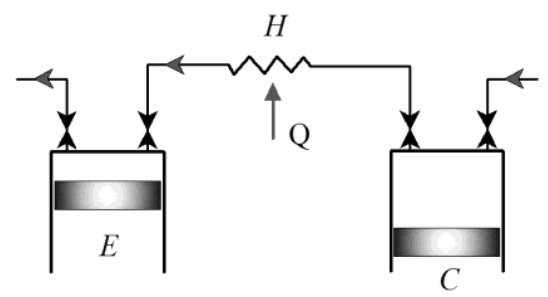

Fig.1: Open cycle Ericsson engine without heat recovery

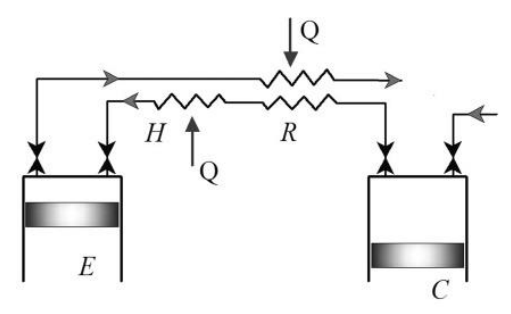

Fig. 2: Open cycle Ericsson engine with heat recovery

In operating conditions where the expanded air is discharged to the ambient pressure, the temperature at the end of expansion is greater than that of the end of the compression, due to the low pressure conditions considered in this study. Therefore, it is possible to use this hot air flow from the expansion cylinder to preheat the gas discharged from the compressor. This operation aims firstly, to reduce the external heat input required to operate the cycle, and secondly, to value the expander exhaust gas which otherwise would have lost their exergy in the environment. This is precisely the role that will play the regenerative heat exchanger $R$ in the Ericsson engine configuration studied and shown in Figure 2.

\section{System modelling}

The engine model is developed on the basis of the mass and energy balance equations applied to control volumes of its four main components shown in figure
2. This model takes into account the evolution over time of mass, pressure and temperature of the working fluid in the control volumes and interfaces, as well as heat transfer in the heat exchangers and dynamic of the valves in the working cylinders. The model considers only losses associated with the gas flowing in and out of the valves.The air used as the working fluid is considered as an ideal gas. Moreover, all its thermophysical properties are supposed to be constant.

The models of the compressor, the heater and the expansion cylinder forming the installation of Figure 1 have been developed on the basis of these assumptions in a previous study by Lontsi et al. (Lontsi, et al, 2013). The new configuration of the studied engine incorporates a recuperator for heat recovery. The model of this component is developed and coupled to that described in (Lontsi, et al, 2013) in such a way as to form the global studied system according to the scheme in Figure 2. Thus, in what follows, only the model of the recuperator will be developed, in accordance with the assumptions made below.

\section{Modelling of Recuperator}

The recuperator considered in this study is a shell-andtube counter-flow heat exchanger (figure 3) in which the hot air from the expansion cylinder exhaust flows inside the tubes (hot compartment of the recuperator) while the compressed air from the compressor flows outside the tubes (cold compartment of the recuperator). This heat exchanger technology was chosen for its simplicity in terms of construction, durability and low cost under very severe working conditions due to high temperatures and pressure differences between the two fluids. The heat exchanger processes are modelled assuming that the spatial variations of the gas parameters along the recuperator are not taken into account. This leads us to consider only the time-dependent relations. Given the assumptions made above, the mass, the temperature and the pressure in each of the two compartments of the recuperator are assumed to be uniform and determined by integration of equations(1), (2) and(3) as follows:

$$
\begin{aligned}
& \frac{d M}{d t}=\dot{m}_{\text {in }}-\dot{m}_{\text {out }} \\
& \dot{\mathrm{Q}}-\dot{W}=c_{v} T \frac{d M}{\mathrm{dt}}+c_{v} M \frac{d T}{d t}+c_{p}\left(\dot{m}_{\text {out }} T_{\text {out }}-\dot{m}_{\text {in }} T_{\text {in }}\right) \\
& \frac{d p}{d t}=p\left(\frac{1}{M} \frac{d M}{d t}+\frac{1}{T} \frac{d T}{d t}-\frac{1}{V} \frac{d V}{d t}\right)
\end{aligned}
$$

Since the volumes are constant and there is no work produced in the recuperator, $\frac{d V}{d t}=0$ and then $\dot{W}=0$.

It is also assumed that the recuperator is insulated (heat losses are negligible) and that in addition, the 
temperature gradient due to conduction through the tube walls is negligible (metallic tubes with low thickness and high thermal conductivity). Under these conditions, heat transfer between the hot tube-side flow and the cold shell-side flow are modeled by the equations of convection between these flows and the respective walls tubes as follows:

$$
\dot{Q}=h . S . \Delta T
$$

For turbulent flow in cylindrical pipe, the Nusselt number on which depends the convective heat exchange coefficient is given by the following DittusBoelter correlation (Incropera and DeWitt, 2001):

$N_{u}=\frac{h d_{t}}{k}=0,023 \operatorname{Re}^{0,8} \operatorname{Pr}^{0,4}$

This correlation is valid under conditions where:

$\frac{L_{t}}{d_{t}} \geq 60 ; 0,7 \leq \operatorname{Pr} \leq 120 ; 10^{4}<\operatorname{Re}<1,2.10^{5}$

In the case of a laminar flow established in the cylindrical pipe, the Nusselt number is calculated using Kays correlation (Sacadura, 2000):

$$
N u=\frac{h d_{t}}{k}=3,66+\frac{0,104\left(R_{e} P_{r} d_{t} / L_{t}\right)}{1+0,016\left(R_{e} P_{r} d_{t} / L_{t}\right)^{0,8}}
$$

When calculating the convection inside the tubes, the Reynolds number in equations (5) and (6) takes into account the internal diameter of the tubes. When calculating the convection in the shell, the Reynolds number considers the equivalent diameter defined by equation (9). Furthermore, the flow rates considered in calculating the Reynolds number are the average of the inflow and outflow of each of the two circuits of the heat exchanger, given that the pressure losses are neglected there.

Considering that the tubes inside the shell are arranged on a network in six-sided polygon, the diameter of the shell is then calculated from the following formula (Gregory and Zorin, 1981):

$$
D=1,1 s \sqrt{n_{t}}
$$

In this formula, $s$ represents the distribution pitch of the tubes in the bundle and its value is chosen in the range defined by the following inequality:

$$
1,3 d_{\text {ext }} \leq s \leq 1,6 d_{\text {ext }}
$$

The expression of the equivalent diameter depends on the configuration of the tubes in the shell. For the triangular configuration which was adopted (Figure 3), it is computed by the following expression:

$D_{h}=\frac{4 A}{P}=\frac{4\left(0.86 s^{2}-\frac{\pi d_{e x t}^{2}}{4}\right)}{\pi d_{e x t}^{2}}$
The heat exchange area in the regenerator is then calculated as follows:

$$
S_{r h}=\pi d t \cdot L_{t} \cdot n t
$$

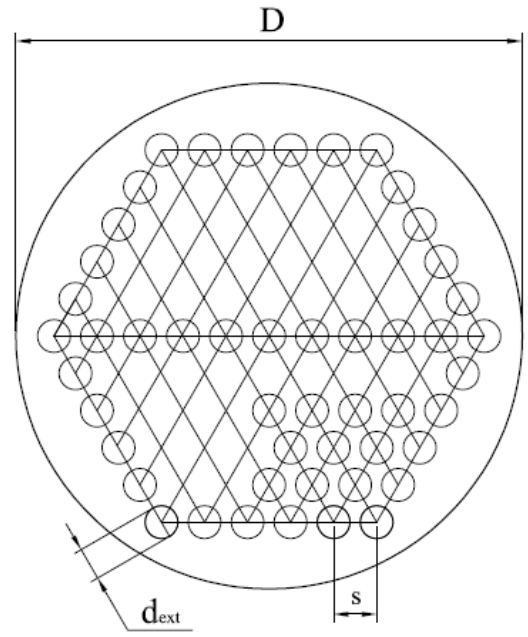

Fig. 3 Triangular pitch tubes assembly

To determine the geometric characteristics of regenerator taking into account the relations (7), (8), (9) and (10) above, it is necessary to set some of parameters such as: the heat exchange area, the diameter or the tube thickness. The characteristics adopted for this study are listed in Table 1.

\section{Global Model}

The parameters concerning the compressor, the expansion cylinder and the heater are taken from the study conducted by Lontsi (Lontsi, et al, 2013) to model de open Joule cycle Ericsson engine without heat recovery. This study made it possible to model the working cylinders kinematic, the compression power $\dot{W}_{c}$, the expansion power $\dot{W}_{e}$, the thermal power of the heater $\dot{Q}_{h}$ and the parameters (p, T, V, M) in each of the control volumes and at the interfaces. The overall model of the installation is then obtained by integrating that of the recuperator as developed above so as to form the open cycle Ericsson engine with heat recovery.

Table 1 Recuperator specifications

\begin{tabular}{cl}
\hline Parameter & Value \\
\hline Heattransfer area, $\left[\mathrm{m}^{2}\right]$ & 5.33 \\
Diameter of tubes, [m] & 0.010 \\
Tubethickness, [m] & 0.001 \\
Number of tubes & 53 \\
Diameter of shell, [m] & 0.147 \\
Tube pitch, [m] & 0.012 \\
\hline
\end{tabular}

From the known parameters, it is then possible to calculate the thermal efficiency based on the resulting cycle work and the heat absorbed in the heater (per unit time) as follows: 


$$
\eta=100 \times \frac{\dot{W}_{e}+\dot{W}_{c}}{\dot{Q}_{h}}
$$

In the following, simulation results are given thanks to the variables-per-cyles data calculated as follows:

$$
\bar{X}=\frac{\int_{\tau}^{\tau+T} X d \tau}{T}
$$

\section{Simulation results}

The developed model was simulated in the Matlab/Simulink environment. The Solver ode23 based on an explicit Runge-Kutta $(2,3)$ was used with a maximum step size of $2 \times 10^{-4} \mathrm{~S}$.

It should be noted that the developed model simulates the engine operation only from the hot startup when wall temperature of the main components are considered constant. Thus, the thermal inertia of metallic parts is not taken into account.

\subsection{Dynamic of starting and stability of the system}

At the beginning of the simulation, pressure in the two cylinders, the heater and the recuperator is equal to atmospheric pressure and temperature equals $300 \mathrm{~K}$. The start-up of the engine begins with the assumption that the temperature of the internal walls of the heater's tubes is constant and equals the fixed value of $873 \mathrm{~K}$. This is to maintain the same simulation conditions as in the study (Lontsi, et al, 2013). The pressure adopted for the operation of the engine is maintained at 4 bar. For this purpose, valve adjustment is carried out to ensure the proper level of pressure in the system given the volume induced by the presence of the recuperative heat exchanger. Preliminary simulations have thus made it possible to determine the following valve timings:

- The opening of the inlet and exhaust valves of the compressor is delayed to angles equal respectively, to $44^{\circ}$ and $120^{\circ}$;

- The closing of inlet and exhaust valves of the expander are advanced by angles respectively equal to $108.7^{\circ}$ and $27^{\circ}$.

Adjusting the valves being performed, the start-up of the engine is simulated over 160 rotation cycles of the crankshaft so as to allow visualization of transient on all the three phases (pressurization of the engine, beginning of the expansion of hot gases and stabilization of the system) as described in (Lontsi, et al, 2013). The comparison between the compressor exhaust and the expansion inlet gas flow rate was adopted to analyze the engine start-up dynamic. Figure 4 shows the evolution of the representative curve of this startup dynamic. The curve begins with an irregular and negative part which corresponds to the pressurization phase of the system where only the compressor operates in order to fill the volume of the heat exchangers upstream of the expander. A zoom on this portion indicates that it lasts $0.2 \mathrm{~s}$.

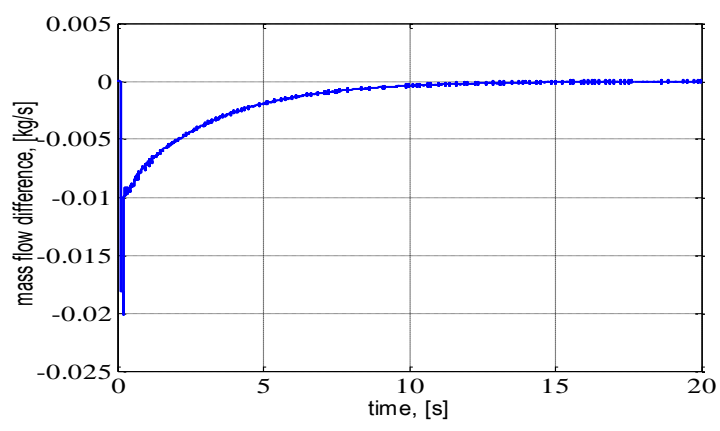

Fig.4 Dynamic of the mass flow rate difference between the expander and the compressor

Then, while remaining negative, the curve increases with a positive slope reflecting the rise of the flow of the expansion cylinder: it is the second phase of the transient that will have begun with the release of the intake valve of the expander. As the compressor pressurizes the system, its mass flow rate will drop while that of the expander will gradually increase. Upon reaching the set pressure, the two flows will equalize and the curve will remain monotonous with a zero slope. This flow rate equilibrium, which occurs after 12.8 seconds after starting the engine, marks the end of the start-up transient and the beginning of the steady state that characterizes the third and last phase of engine startup. The duration of the start-up transient is naturally longer than that obtained in the previous work (Lontsi, et al, 2013), because of the presence of the recuperator in the new configuration of the engine. This will have led to an increase in the volume to be pressurized upstream of the expander, as well as additional time required to ensure heat exchange in the additional volumes of the recuperator. However, it must be remembered that the thermal inertia of the wall of the heat exchangers is not taken into account in the developed model of the engine. In practice, the startup will be much longer because of the heat that must first be accumulated in the solid walls of the system heat exchangers. Under the obtained stable operating conditions the engine develops an output of $1.89 \mathrm{~kW}$ and a thermal efficiency of about $37 \%$.

\subsection{Analysis of the operation of the recuperator}

The design and proper operation of this heat exchanger are decisive for improving system performances. For a given flow rate of the working fluid and for given temperatures at the inlet of the recuperator, heat exchange surface area, the heat transfer coefficient and the efficiency are the main variables which make it possible to determine the geometry, the temperatures at the outlet as well as the amounts of heat recovered per unit of time. In the developed model, the heat exchange surface area was set so as to fix the ideas on 
the geometric configuration of the recuperator. In view of the simulation results, when the system stabilizes, the heat convection coefficients on both the inner wall and the outside of the tubes are small and correspond to laminar flows. In fact, the engine is very slow (480 $\mathrm{rpm}$ ) and the rate at which air flows is on average 6.19 $\mathrm{m} / \mathrm{s}$ within the tubes and $5.34 \mathrm{~m} / \mathrm{s}$ outside. Overall, in steady-state the recuperator operates with transferred thermal power equal to $764.5 \mathrm{~W}$ and an efficiency of about $43.5 \%$. Since the level of heat exchange is low (laminar flow), only the increase of the heat exchange surface area would improve this efficiency in the context of an open Joule cycle with heat recovery. However, a large surface area would result in the construction of a less compact and necessarily more expensive heat exchanger.

In Figure 5 are shown the evolution of temperatures in tubes (dotted line) and in the shell (solid line) of the recuperator during the engine startup as described above. It appears on the zoomed part shown in figure 6 that, during pressurization of the system, the circuit upstream of the expander is warmer than that downstream. So that it is rather the 'cold compartment' of the recuperator that is goingto transfer heat to the 'hot compartment'. This trend will continue even after the expansion process started (when the system pressure reaches 2 bar and the valves of the expansion machine are released). This trend will continue even after the expansion process started (when the pressure reaches 2 bar upstream of the expansion cylinder).

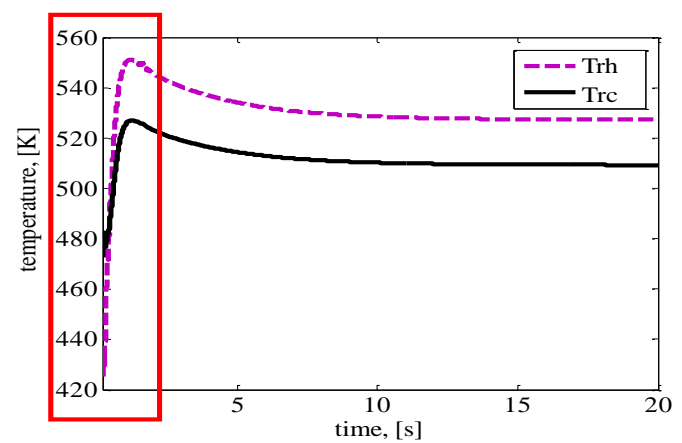

Fig.5 Evolution of temperatures in the two compartments of the recuperator

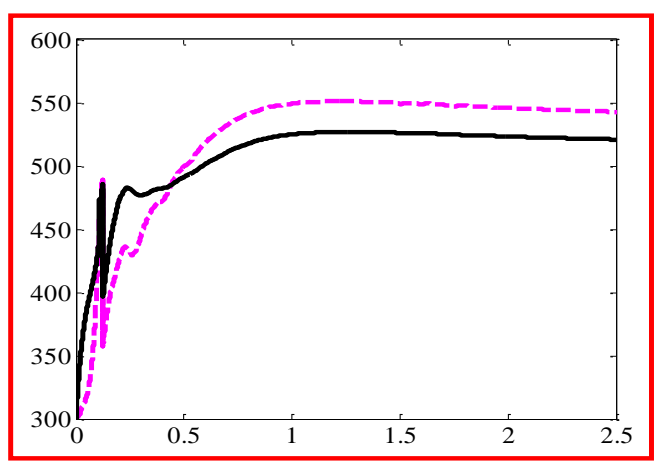

Fig.6 Zoom from fig.5
Halfway through the third cycle (when $\tau=0.44 \mathrm{~s}$ and $\mathrm{p}=2.3 \mathrm{bar}$ ), temperatures equalize in the two compartments of the regenerator and subsequently, the trends are reversed.

It is precisely from this moment that this heat exchanger starts operating in 'heat recovery' mode: the energy recovered from the expander exhaust gases is transferred to those discharged by the compressor, thereby helping to preheat the air that is introduced into the heater.

After transferring heat in the regenerator, the expander exhaust gases are released at atmospheric pressure; but at a temperature such that the thermal content (986.7 Joules per second) makes this flow of gas viable for energy valorization. In fact, under the modeling conditions when the operating regime is stabilized, the air flow exits the recuperator at a temperature of $529.5 \mathrm{~K}$. And with such a temperature level, this air flow could provide heat to be used for instance to cover heating needs, domestic hot water or even for cold production by absorption or ejection refrigerating systems. Simultaneous production capacity of mechanical and thermal energies testifies to the high potential of the open Joule cycle Ericsson engine as regards its implementation in microcogeneration systems.

\subsection{System response to a selected disturbance and performance dynamic}

In the study conducted by Lontsi at al. (Lontsi, et al, 2013), the engine was subjected to three types of disturbances in order to study the dynamic behaviour of the transients resulting from them, how they influence the system's stability and how they impact the engine's performances. In the new configuration of the engine whose model is developed here, the simulation of only one of these disturbances has been carried out under the same conditions, so as to be able to make comparisons on the results. This perturbation has to do with simulating a sudden drop of the compressor inlet pressure of $10 \mathrm{kPa}$ after the engine starts and stable operation been established. Such a drop is practically possible and could for instance be the result of the plugging of the atmospheric air filter in the suction line. The transients resulting from this disturbance are visualized using the illustrations of Figures 7 and 8.

Having carried out the simulations under the same conditions, the PV diagram and the curve representing the dynamic of the thermal efficiency of the engine show that, the transients look similar to those obtained in (Lontsi, et al, 2013). However, it should be noted here that the disturbance will have caused a reaction of the system which results in a transient of much longer duration compared to that recorded in the study (Lontsi, et al, 2013) with a lengthening of the transition time between the two stability states which is due to the presence of the additional volume imposed by the presence of the recuperator. 
The curve in figure 7 shows that at the end of the perturbation the compressor indicator diagram moves downwards, after having cross a transient phase as depicted. Figure 8 shows the phenomenon with regard to the dynamic of the engine's thermal efficiency. The impact of the disturbance is reflected in the pressure drop in the engine (from 4 to 3.7 bar), while the system efficiency also drops and then stabilize at $33.4 \%$ (compared to its $37.13 \%$ value before the disturbance).

The Ericsson engine is an externally heated thermal engine whose operation requires the consumption of available energy resources. The engine converts a fraction of the energy of these resources to make it usable in other forms including mechanical and thermal. As mentioned earlier, the configuration of the Ericsson engine including the recuperator is essentially aimed at improving system performance. An assessment is made using the thermal efficiency that has been defined and expressed by the relation (11). This thermal efficiency in accordance with this relationship, increases as the heat input into the heater decreases. In this case, as was noted above, the reduction of heat input into the heater is attributable to the heat recovery using the recuperator. The amount of heat per unit time transferred by the latter upstream of the heater represents $15 \%$ of the total thermal power input of the engine. The dynamic of the engine's thermal efficiency is well illustrated in dashed lines of figure 8. Based on data when the engine operates under stable conditions, it can be seen that taking into account heat recovery significantly improves the performance of the open Joule cycle Ericsson engine. In fact, by incorporating the recuperator in the new model, the simulations indicate $21 \%$ increase of the thermal efficiency compared to the data of (Lontsi, et $a l, 2013)$. Apart from that, the engine power output also experienced an increase although relatively low $(14.3 \%)$. The variation of the power output observed is explained by the fact that it was necessary to readjust the valves so that at the end of the start-up transient the operation of the system stabilizes at 4 bar, which is the set pressure adopted in the two studies for the purpose of comparing the results. This has also caused a slight increase in temperature at the intake of the expansion cylinder ( $809 \mathrm{~K}$ in the study (Lontsi, et al, 2013) against $815 \mathrm{~K}$ in the present study).

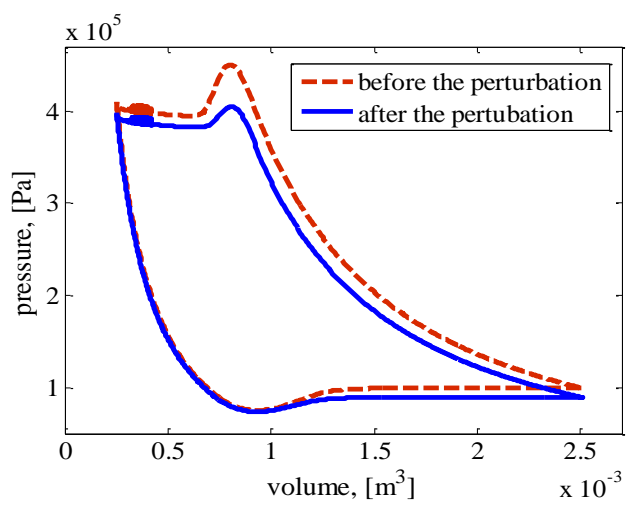

Fig.7 PV plot of the compressor before and after the disturbance

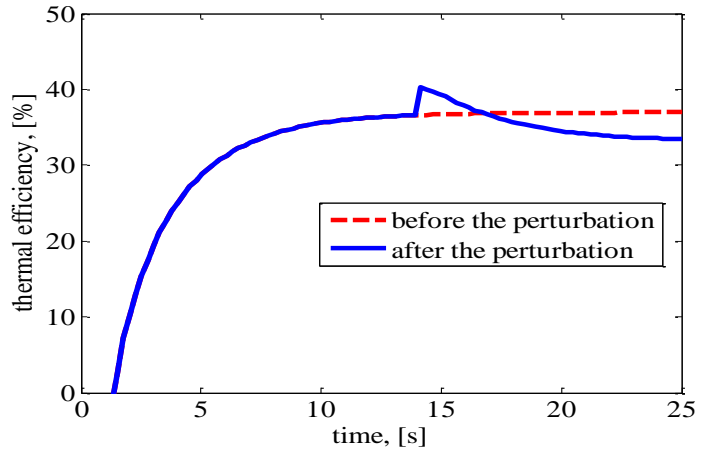

Fig.8 Dynamic of the engine thermal efficiency

Despite the improvement due to the use of heat recovery, the engine performances obtained based on the developed model remain inferior to those of the corresponding theoretical open Joule cycle. This is explained by the fact that the engine thermal efficiency calculated on the basis of the proposed model assumes the recuperator efficiency equal to $44 \%$ (not $100 \%$ as in an ideal corresponding cycle) and, moreover, pressure drops are taken into account during the flow of gas through all the valves of the compression and expansion cylinders (however negligible as regards the theoretical cycle).

\section{Conclusion}

A dynamic model of an open Joule cycle Ericsson engine with a shell-and-tube counter-flow regenerative heat exchanger was developed and simulated. This model is based on the assumption of the ideal gas and the energy and mass conservation principles applied to the different control volumes of the system. Compared to the engine configuration without regeneration, simulation results predict a slower hot start-up transient followed by a stable operation of the engine with significantly improved performance $(21 \%$ increase of the thermal efficiency and 14.3\% increase of the engine power output thanks to heat recovery of hot gases downstream the expander).

Subjected to a selected perturbation $(10 \mathrm{kPa}$ compressor inlet pressure drop) the engine reacts well and the operation is stabilized after a much longer transient phase compared to that recorded concerning the open Joule cycle Ericsson engine without heat regeneration in the same simulation conditions.

Under the stabilized operating conditions, the air flow exits the recuperator at $529.5 \mathrm{~K}$. With such a temperature level, this exhaust air flow could provide heat used for instance to cover heating needs, domestic hot water or even for cold production using absorption or ejection refrigerating systems. Simultaneous production capacity of mechanical and thermal energies testifies to the high potential of the open Joule cycle Ericsson engine as regards its implementation in micro-cogeneration systems. 


\section{References}

Stouffs P (2002). Le moteur Ericsson, un moyen de valorisation de l'énergie thermique à réhabiliter ? Entropie. 241, pp 26-32.

Lontsi F, Hamandjoda O, Djanna KF, Stouffs P, Nganhou J (2013). Dynamic modeling of a small open Joule cycle reciprocating Ericsson engine: simulation results. Energy Sciences and Engineering. 1(3):109-117.

Bonnet S, Alaphilippe MT, Stouffs P (2005). Energy, exergy and cost analysis of a micro-cogeneration based on an Ericsson engine. Int. J. Therm. Sci. Vol. 44, $\mathrm{N}^{\circ} 12$, p.11611168.

Bell M A, Partridge T (2003). Thermodynamic design of a reciprocating Joule cycle engine. Proc. Instn. Mech. Engrs. Vol.217 Part A: J. Power and Energy.

Moss R W, Roskilly A P, Nanda S K (2005). Reciprocating Joule-Cycle engine for domestic CHP systems. Applied Energy. 80, 169-185.

Creyx M, Delacourt E, Morin C, Desmet B, Peultier P (2013). Energetic optimization of the performance of a hot air engine for micro-CHP systems working with a Joule or an Ericsson cycle. Energy. 49:229-239.

Touré A, Stouffs P (2014). Modeling of Ericsson engine. Energy. 76:445-452.

Hachem H, Creyx M, Gheith R, Delacourt E, Morin, Aloui F, Nasrallah SB (2015). Comparison based on exergetic analysis of two hot air engines: A gamma type stirling engine and an open Joule cycle Ericsson engine. Entropy. $17: 7331-7348$.

Wojewoda J, Kazimierski Z (2010). Numerical model and investigations of the externally heated Joule engine Energy. 35: 2099-2108.

Frederic Lontsi, Oumarou Hamandjoda, Kennedy Fozao, Pascal Stouffs, Jean Nganhou (2013). Dynamic simulation of a small modified Joule cycle reciprocating Ericsson engine for micro-cogeneration systems. Energy. 63; 309316.

M. Creyx, E. Delacourt, C. Morin, B. Desmet (2016). Dynamic modelling of the expansion cylinder of an open Joule cycle Ericsson engine: A bond graph approach. Energy. 102;3143.

Dorin Stanciu, Viorel Badescu (2017). Solar-driven Joule cycle reciprocating Ericsson engines for small scale applications. From improper operation to higher performance. Energy Conservation and Management. Vol. 135: p.101-116.

M. Alaphilippe, S. Bonnet, P. Stouffs (2007). Low power thermodynamic solar energy conversion: coupling of a parabolic trough concentrator and an Ericsson engine. Int. J. of Thermodynamics, $\mathrm{N}^{\circ} 10$, p. 37-45,
Frank P. Incropera, David P. DeWitt (1996). Fundamentals of heat and mass transfer. John Wiley \& Sons, fourth ed.

J. F. Sacadura (2000). Initiation aux transferts thermiques. Editions TEC\& Doc.

Gregory \& Zorin (1981). Industrial energy engineering. Energoatomisdat. Moscow.

\section{Nomenclature}

$A \quad$ surface area, $\left[\mathrm{m}^{2}\right]$

$c_{p} \quad$ specific heat of air at constant

pressure, [J/kg.K)]

$c_{V} \quad$ specific heat of air at constant

volume, [J/kg.K]

$d \quad$ diameter, $[\mathrm{m}]$

$D$ shell diameter, [m]

$h$ heat exchange coefficient, $\left[\mathrm{W} /\left(\mathrm{m}^{2} . \mathrm{K}\right)\right]$

$k$ thermal conductivity, [W/(m.K)]

$L \quad$ length, $[\mathrm{m}]$

$M$ masse, [kg]

$\dot{m} \quad$ masse flow rate, $[\mathrm{kg} / \mathrm{s}]$

$p$ pressure, $[\mathrm{Pa}]$

$P$ perimeter, $[\mathrm{m}]$

$\dot{Q} \quad$ thermal power, [W]

$S$ heat exchange surface area, $\left[\mathrm{m}^{2}\right]$

$t$ time, [s]

$T$ temperature, $[\mathrm{K}]$ or period, $[\mathrm{s}]$

$V \quad$ volume, $\left[\mathrm{m}^{3}\right]$

$\dot{W}$ power, [W]

$\bar{X}$ mean value for the parameter $\mathrm{X}$

\section{Greek letter}

$\eta \quad$ engine thermal efficiency, [\%]

\section{Subscripts}

c compressor

e expander

ex external

$h$ heater

in into the control volume, inlet

out out of the control volume

$r c$ recuperator, cold shell-side

$r h$ recuperator, hot tube-side

$t$ tube 